1966) and in some middle-aged women presenting with cryptogenic cirrhosis (Ross et al., 1972).

The two patients in the present family did not show the typical clinical picture of either active chronic hepatitis or cryptogenic cirrhosis and they have not progressed to hepatic decompensation even after long follow-up. Similar lack of evidence of progression may be seen in the subclinical hepatitis associated with collagenosis or thyroiditis and mitochondrial antibodies in the serum (Walker et al., 1970). It is of interest that both our patients had a goitre and thyroid antibodies. The history in the mother was similar to that in the sister of the proband but in the absence of laboratory or histological information the nature of her illness remains obscure.

None of the relatives examined had clinical evidence of hepatic or thyroid disorder. One of the brothers with mitochondrial antibodies had mildly raised bromsulphalein retention, but in the other 11 relatives biochemical tests were normal. Liver histology was not available and no conclusions can be reached regarding the possibility of subclinical hepatic lesions. Besides the mitochondrial reactions half of the family members had thyroid antibodies, and one brother had a biological false-positive reaction for syphilis. This may be associaated with collagenosis (Doniach et al., 1970) and sometimes with subclinical hepatitis (Walker et al., 1970).

The family reported illustrates the clustering of mitochondrial and other tissue antibodies and clinical liver disease akin to primary biliary cirrhosis occurring in association with thyroid autoimmunity. None of the members had the Australia antigen in the serum and it is unlikely that the virus of longincubation hepatitis plays any part in the pathogenesis of primary biliary cirrhosis (Doniach et al., 1971). Of the 27 families studied by Feizi et al. (1972), in only one other was there a parent with possible cirrhosis, though $7 \%$ of the relatives had mitochondrial antibodies, as compared with less than $1 \%$ in the general hospital population.

\section{References}

Block, M. A., LoGrippo, G. A., and Fox, T. A. (1969). American fournal of Surgery, 117, 69.

Cavell, B., and Leonhardt, T. (1965). Acta Medica Scandinavica, 177, 751.

Doniach, D., Roitt, I. M., Walker, J. G., and Sherlock, S. (1966). Clinical and Experimental Immunology, 1, 237.

Doniach, D., Delhanty, J., Lindqvist, H. J., and Catterall, R. D. (1970). Clinical and Experimental Immunology, 6, 871.

Doniach, D., Del Prete, S., Dane, D. S., and Walsh, J. H. (1971). Canadian Medical Association fournal. In press.

Elling, P., Ranlov, P., and Bildsoe, P. (1966). Acta Medica Scandinavica, $179,527$.

Feizi, T., Naccarato, R., Doniach, D., and Sherlock, S. (1972). Clinical and Experimental Immunology. In press.

Joske, R. A., and Laurence, B. H. (1970). Gastroenterology, 59, 546.

McConnell, R. B. (1966). The Genetics of Gastrointestinal Disorders, p. 200, London, Oxford University Press.

Maddrey, W. C., and Iber, F. L. (1964). Annals of Internal Medicine, 61,

Ohbayashi, A., Mayumi, M., and Okochi, K. (1971). Lancet, 1, 244.

Pollak, V. E. (1964). New England fournal of Medicine, 271, 165.

Prince, A. M., and Burke, K. (1970). Science, 169, 593.

Roitt, I. M., and Doniach, D. (1969). Manual of Autoimmune Serology. Geneva, World Health Organization.

Ross, A., Scheuer, P. J., Fox, R. A., Sherlock, S., and Doniach, D. (1972). In preparation.

Scheuer, P. J. (1968). Liver Biopsy Interpretation, p. 22. London, Baillière, Tindail and Cassell.

Walker, J. G., and Doniach, D. (1971). In Immunology of the Liver, ed. M. Smith and R. S. Williams, p. 55. London, Heinemann. Walker, J. G., Doniach, D., and Doniach, I. (1970). Quarterly fournal of
Medicine, 39, 31.

\title{
Effect of Rifampicin and Isoniazid on Liver Function
}

\author{
SATINDER LAL， S. N. SINGHAL， D. M. BURLEY， G. CROSSLEY
}

British Medical fournal, 1972, 1, 148-150

\section{Summary}

The effects of rifampicin and isoniazid on liver function have been studied in 63 patients with pulmonary tuberculosis; $29 \%$ showed abnormalities of serum aspartate aminotransferase (SGOT) and a similar percentage abnormalities of serum bilirubin. These usually occurred during the first 12 weeks of therapy. The average duration of the abnormalities was $14 \frac{1}{2}$ days, irrespective of whether treatment was interrupted or not.

The relationship between raised SGOT and acetylator phenotype in a small number of patients suggests that those with raised SGOT are usually slow acetylator phenotypes. It seems that hepatic reactions in patients with previously normal liver function are usually mild and non-specific. However, patients who continue with rifampicin should be kept under close biochemical observation.

General Hospital, Bury, Lancashire

SATINDER LAL, M.B., B.S., F.R.C.P., Consultant Physician

S. N. SINGHAL, M.B., B.S., Clinical Assistant, Chest Unit

G. CROSSLEY, F.I.M.L.T., Biochemist

CIBA Laboratories, Horsham, Sussex

D.-M. BURLEY, M.B., B.S., Head of Medical Services

\section{Introduction}

Numerous reports have now been published showing rifampicin to be a potent antituberculous drug in both animal and human studies, comparable with isoniazid in its activity (Grumbach and Rist, 1967; Pines et al., 1967; Cannetti et al., 1968; Verbist and Gyselen, 1968; Gyselen et al., 1969; Dormer and Salinger, 1971; Newman et al., 1971; Nitti et al., 1971; Pines, 1971). In contrast with streptomycin it is effective orally, and it is much more palatable than para-aminosalicylic acid. Its use in combination with isoniazid, therefore, promises to be an ideal regimen. Initial studies with rifampicin in combination with other agents indicated that in the early weeks of therapy transient rises in serum bilirubin might occur, together with small changes in liver enzyme tests, but it was felt that these could be explained because the principal excretion pathway for the antibiotic was through the biliary tract, and there was direct competition with the excretion of bilirubin (Cohn, 1969). Overt liver damage from rifampicin was rare, though preexisting liver damage could be aggravated (Lesobre et al., 1969).

We now describe our experience of hepatic reactions from treating 63 patients ( 39 males and 24 females aged 8 to 80 years) suffering from pulmonary or lymph-node tuberculosis with, initially, a triple drug regimen including rifampicin. All were treated with streptomycin $0.75 \mathrm{mg}$ daily, isoniazid $300 \mathrm{mg}$ daily, and rifampicin $450 \mathrm{mg}$ in patients weighing less than $50 \mathrm{~kg}$ or $600 \mathrm{mg}$ in patients weighing $50 \mathrm{~kg}$ or more. If sensitivity testing showed that the patient's organisms were sensitive to rifampicin and isoniazid then the streptomycin was dropped, usually between the 8 th and 12 th weeks of therapy. 
Liver function was monitored by measuring bilirubin with the Molloy and Evelyn method and the serum aspartate aminotransferase (SGOT) by the standard automated Babson technique on the Technicon AutoAnalyzer, before starting treatment, twice weekly for the first two months of therapy, weekly for the next month, and finally at monthly intervals until the completion of treatment. Sixteen patients also had their acetylator phenotype assessed by the method of Price Evans (1969). Some patients showing adverse reactions also had needle biopsy of the liver performed, but this will be reported separately.

\section{Results}

Table I gives the number of patients showing rises of SGOT and bilirubin at different levels. SGOT levels of up to $40 \mathrm{units} / \mathrm{ml}$ are considered normal in our laboratory, and $31(49 \%)$ of the 63 patients were in this group. Fourteen patients $(22 \%)$, however, showed a single rise of between 41 and 60 units at some time or other during their treatment period, the earliest being at two weeks and the latest at 40 weeks. These were also considered to be probably normal, as in all cases where rises above 60 units were seen the abnormality was recorded on more than one consecutive occasion. Eighteen patients $(29 \%)$ were considered abnormal by these criteria, with the abnormality persisting for an average period of 14 days (see Table III). Altogether, "abnormal episodes" were encountered on 27 separate occasions, and Table II shows the relationship of this rise in SGOT to the duration of therapy. It will be noted that $78 \%$ of these occurred in the first 12 weeks.

TABLE I-SGOT and Bilirubin Levels in 63 Patients

\begin{tabular}{|c|c|c|c|}
\hline \multicolumn{2}{|l|}{ SGOT } & No. of Patients & $\begin{array}{l}\text { Raised Bilirubin in this } \\
\text { Group }\end{array}$ \\
\hline 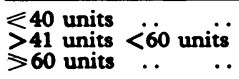 & $\begin{array}{l}\ldots \\
\cdots\end{array}$ & $\begin{array}{l}31(49 \%) \\
14(22 \%) \\
18(29 \%)\end{array}$ & $\begin{array}{l}2(3 \%) \\
9(14 \%) \\
7(11 \%)\end{array}$ \\
\hline Bilirubin & & No. of Patients & SGOT $>60$ in this \\
\hline $\begin{array}{ll}<1 \mathrm{mg} / 100 \mathrm{ml} & \ldots \\
1.0-1.5 \mathrm{mg} / 100 \mathrm{ml} & \ldots \\
1.6-2.0 \mathrm{mg} / 100 \mathrm{ml} & \ldots \\
>2 \mathrm{mg} / 100 \mathrm{ml} & \ldots\end{array}$ & $\begin{array}{l}\ldots \\
\cdots \\
\cdots\end{array}$ & $\begin{array}{l}45(71 \%) \\
9(14.5 \%) \\
4(6.5 \%) \\
5(8 \%)\end{array}$ & $\begin{array}{cl}12 & (19 \%) \\
3 & (4 \cdot 8 \%) \\
2 & (3 \%) \\
1 & (1.5 \%)\end{array}$ \\
\hline
\end{tabular}

TABLE II-Raised SGOT Levels on 27 Occasions in 18 Patients

\begin{tabular}{l|c|c|c|c|c|c}
\hline Week & 2 & 4 & 8 & 12 & 26 & $26+$ \\
Cumulative occurrence & $\begin{array}{c}6 \\
(22 \%)\end{array}$ & $\begin{array}{c}13 \\
(48 \%)\end{array}$ & $\begin{array}{c}18 \\
(66 \%)\end{array}$ & $\begin{array}{c}21 \\
(78 \%)\end{array}$ & $\begin{array}{c}24 \\
(88 \%)\end{array}$ & $\begin{array}{c}27 \\
(100 \%)\end{array}$ \\
\hline
\end{tabular}

Nine patients $(14.5 \%)$ showed a rise in bilirubin above $1.5 \mathrm{mg} / 100 \mathrm{ml}$ and four of these had clinically recognizable jaundice with 2 to $4.2 \mathrm{mg}$ of bilirubin per $100 \mathrm{ml}$. A further nine patients showed bilirubin levels between 1 and $1.4 \mathrm{mg}$ / $100 \mathrm{ml}$ at some time.

Initially in the study when a raised SGOT was observed the patient's treatment was discontinued and the biochemistry checked twice weekly. However, there was a delay in the receipt of results in one patient and it was noted that a second SGOT value was already falling, despite the fact that rifampicin had not been discontinued. Because of this observation patients have latterly been kept on rifampicin despite a rise of SGOT levels and close biochemical supervision has been maintained, bilirubin and SGOT being measured twice weekly. Table III shows the duration of raised SGOT in the two groups of patients: those who discontinued rifampicin for a period and those who did not. The differences in average duration of biochemical abnormalities was not significantly different in the two groups, but the groups are not comparable as they were in separate periods. There were two patients with raised bilirubin in the first group (1.4 and $4.2 \mathrm{mg}$ ) and four in
TABLE III-Duration of Raised SGOT in Patients with and without Discontinuation of Rifampicin

\begin{tabular}{l|c|c}
\hline & Treatment Stopped & Treatment Not Stopped \\
\hline $\begin{array}{l}\text { No. of patients } \\
\text { Duration (days) }\end{array}$ & 5 & $14, * 10,19,16, * 13$ \\
\hline Mean & $14 \cdot 4$ days & $14, * 10,20,7,7,22, * 6,21,8,20$, \\
\hline
\end{tabular}

- Raised bilirubin also.

TABLE IV-Capacity to Acetylate Sulphadimidine in 16 Patients

\begin{tabular}{|c|c|c|c|c|}
\hline & & & Raised SGOT Group & Normal \\
\hline $\begin{array}{l}\text { Rapid acetylators } \\
\text { Slow acetylators .. }\end{array}$ & $\ddot{x}$ & 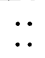 & 8† & $\begin{array}{l}\mathbf{5} \\
\mathbf{2}\end{array}$ \\
\hline Total & .. & .. & 9 & 7 \\
\hline
\end{tabular}

-Raised SGOT and bilirubin †Five patients with raised SGOT and bilirubin and three patients with raised
SGOT alone.

the second group, the levels of bilirubin being $2 \cdot 0,1 \cdot 4,1 \cdot 8$, and $1.2 \mathrm{mg} / 100 \mathrm{mg}$.

Table IV relates the incidence of raised SGOT to acetylator phenotype in the 16 patients who had this assessment carried out. It will be seen that "slow acetylators" with only one exception occurred in the group with raised SGOT whereas "rapid acetylators" predominated in the group showing no liver function abnormalities. The one exception, a rapid acetylator in the raised SGOT group, was a female patient weighing only $45 \mathrm{~kg}$ who had been prescribed $600 \mathrm{mg}$ of rifampicin instead of $450 \mathrm{mg}$ prescribed by the trial plan.

\section{Discussion}

Lesobre et al. (1969) and Lees et al. (1970) advise caution in prescribing rifampicin, particularly when the antibiotic is used in combination with isoniazid, because of the high incidence of hepatotoxicity, especially in patients with liver disease. Our experience in patients with initially normal hepatic function is encouraging. It indicates that the hepatic reactions are not prejudicial to treatment as was at one time suspected. In none of the 63 patients in our series was treatment abandoned because of these reactions; nor does it seem necessary to interrupt it, since the average duration of abnormalities was 14.4 days in patients where this was done and only 14.6 days in patients who continued therapy without interruption.

Both rifampicin and isoniazid are metabolized in the liver, and rifampicin is mostly excreted via the biliary tract. Rifampicin is also deacetylated to deacetyl rifampicin, which is not well reabsorbed from the gut, and isoniazid is acetylated but at two different rates in different individuals. Hepatic reactions to isoniazid have been reported (Scharer and Smith, 1969) and occasionally overt liver damage (Davies and Glowinski, 1961; Reynolds, 1962). Serious hepatotoxicity from the use of isoniazid and rifampicin in combination was first reported by Lesobre et al. (1969), many of whose patients had previously damaged livers, and subsequently Lees et al. (1970) reported, from Great Britain, a high incidence of jaundice in patients receiving this combination. In rats also Hugues et al. (1969) demonstrated histological changes in the liver in those animals receiving isoniazid and rifampicin together, but not when the drugs were given separately.

It seems reasonable to assume that the handling of these two drugs together may place some strain on liver capacity, particularly in subjects whose acetylator phenotype indicates that they metabolize isoniazid slowly.

It is interesting that in our group of nine patients showing liver function abnormalities-that is, raised SGOT and bilirubin in six patients and raised SGOT alone in the other three-eight were "slow acetylators." The numbers are small, and this aspect of drug metabolism would merit further study. 
There seems little doubt, however, that the enzyme-inducing activity of rifampicin enables the liver to handle the two drugs adequately within a few weeks. Few of our cases showed abnormalities of function later than the 12th week, and in the series of Lees et al. the initial reaction occurred within seven weeks with a mode at three weeks.

Histological data are available from liver biopsy in some patients showing hepatic abnormalities, and these data will be reported in detail elsewhere ( $\mathrm{Lal}$ et al., 1972), but in the main they support the view that the reactions are mild and nonspecific.

We have no experience of the use of rifampicin and isoniazid in alcoholic patients or in those with evidence of liver damage from other causes, and we still feel that rifampicin should be avoided in such cases.

We would like to thank Professor Sheila Sherlock and her colleagues for their advice and help in carrying out this study, and we are also grateful to Ciba Laboratories for generous supplies of rifampicin. We would also like to thank the nursing staff of the chest unit for their precise recording of the results.

\section{References}

Cannetti, G., Le Lirzin, M., Proven, G., Rist, N., and Grumbach, F. (1968). Tubercle, 49, 367.

Cohn, H. D. (1969). Fournal of Clinical Pharmacology and fournal of New Drugs, $9,118$.

Davies, D., and Glowinski, J. J. (1961). Tubercle, 42, 504.

Dormer, B. A., and Salinger, P. L. (1971). South African Medical fournal, 45, 697 .

Grumbach, F., and Rist, N. (1967). Revue de la Tuberculose et de Pneumologie, 31, 749.

Gyselen, A., et al. (1969). Acta Tuberculosea et Pneumologica Belgica, 60, 563. Hugues, F. C., Marche, C., and Marche, J. (1969). Therrapie, 24, 899.

Lal, S., et al. (1972). In preparation.

Lees, A. W., Asgher, B., Hasheim, M. A., and Sinha, B. N. (1970). British fournal of Diseases of the Chest, 64, 90 .

Lesobre, R., Ruffino, J., Teyssier, L., Achard, F., and Brefort, C. (1969). Revue de la Tuberculose et de Pneumologie, 33, 393.

Newman, R., Doster, B., Murray, S. J., and Ferebee, S. (1971). American Review of Respiratory Diseases, 103, 461.

Nitti, V., Catena, E., Veneri, F. D., Moora, A., and De Michele, G. (1971). American Review of Respiratory Diseases, 103, 329.

Pines, A. (1971). British fournal of Diseases of the Chest, 65, 178.

Pines, A., Raafat, H., and Bundi, R. (1967). Tubercle, 48, 281.

Price Evans, D. A. (1969). Fournal of Medical Genetics, 6, 405.

Price Evans, D. A. (1969). Fournal of $M$.

Reynolds, E. (1962). Tubercle, 43, 375.
Scharer, L., and Smith, J. P. (1969). Annals of Internal Medicine, 71, 1113.
Verbist, L., and Gyselen, A. (1968). American Review of Respiratory Diseases, 98, 923.

\section{PRELIMINARY COMMUNICATIONS}

\section{Prostaglandin-oxytocin Enhancement and Potentiation and their Clinical Applications}

\author{
ARNOLD GILLESPIE
}

British Medical fournal, 1972, 1, 150-152

\section{Summary}

The pharmacological phenomena of enhancement and potentiation of uterine response occur respectively when combinations of some prostaglandins and oxytocin are given serially and simultaneously to a patient. Employing these phenomena allows small doses of the drugs to achieve the same effects as a large dose given alone. In a pilot study of the use of the combination of prostaglandin and oxytocin for the induction of mid-trimester abortion seven of nine women were aborted within 48 hours. Side effects attributable to prostaglandin were eliminated or reduced in severity.

\section{Introduction}

Brummer (1971) demonstrated in this laboratory that after exposure to the $\mathrm{E}$ prostaglandins human pregnant myometrial strips in vitro show a greater contractile response to a given dose of oxytocin than before the exposure to the prostaglandin. This phenomenon is termed "enhancement." The enhanced response is seen for about one hour after the prostaglandin has been washed out of the water-bath and is peculiar to the $\mathrm{E}$ prostaglandins.

Prostaglandin E or F administered simultaneously with oxytocin exhibits the more usual "potentiation" of effects, in which the total response is greater than that expected by the direct addition of the two separate responses.

\footnotetext{
Institute of Obstetrics and Gynaecology, Chelsea Hospital for Women, London S.W.3

ARNOLD GILLESPIE, M.B., B.S., M.R.C.o.G., Lecturer
}

The possibility of applying the phenomena of enhancement and potentiation clinically to induce mid-trimester abortion has been investigated. The aim of the investigation was to decrease the dose of prostaglandin administered and hence minimize the incidence of troublesome side effects.

\section{Material and Methods}

Patients in the mid-trimester of pregnancy admitted to hospital for hysterotomy were interviewed and offered the possibility of termination of the pregnancy by the vaginal route. The procedure was explained and only volunteers received the drugs.

The oxytocin (Syntocinon) and prostaglandins were administered into a large superficial arm vein through an indwelling polyethylene cannula (Bardic A catheter, $5.5 \mathrm{~cm}$ ) by means of a Palmer constant infusion pump. Uterine activity was monitored via a fluid-filled polyethylene catheter (Portex $90 \mathrm{~cm} \mathrm{100/380/150)} \mathrm{introduced} \mathrm{transabdominally} \mathrm{into} \mathrm{the}$ amniotic sac and connected to a pen recorder (Devices M2) via a semiconductor strain-gauge pressure transducer and appropriate amplifier.

A preliminary investigation was carried out in seven patients. The dose and duration of infusion of prostaglandin $\mathrm{E}_{2}\left(\mathrm{PGE}_{2}\right)$ required to achieve an "enhanced" uterine response to subsequently infused oxytocin was determined. The time after infusion of prostaglandin $E_{2}$ during which the enhanced response could still be obtained was also determined. Finally, the doses of oxytocin infused simultaneously with either prostaglandin $E_{2}$ or prostaglandin $F_{2} \alpha$ to achieve the maximum potentiation of the drug effects were established. The pregnancies were then terminated by infusion of the previously described dose (Karim and Filshie, 1970a, 1970b; Gillespie et al., 1971) of prostaglandin or by intra-amniotic injection of hypertonic saline.

\section{Results}

In Fig. 1 an intra-amniotic pressure tracing from a woman 16 weeks pregnant shows both enhancement and potentiation. Traces $A, B$, and $C$ show the response of the uterus to an infusion of oxytocin progressively increasing from $16 \mathrm{mU} /$ 